\title{
Incidence du retour quotidien en chèvrerie sur le comportement alimentaire et spatial de caprins dans un taillis
}

\author{
B Leclerc ${ }^{1}$, E Lécrivain 2 \\ 1 INRA-SAD Armonique, 65, rue de Saint-Brieuc, 35042 Rennes Cedex; \\ 2 INRA-SAD, unité d'écodéveloppement, domaine Saint-Paul, 84140 Montfavet, France
}

Le régime alimentaire des herbivores résulte d'une série de choix de plantes qui se succèdent durant la journée au rythme de leurs déplacements au sein d'une mosaïque d'associations végétales. Ces déplacements peuvent-ils être influencés par la conduite au pâturage adoptée par l'éleveur? Nous avons analysé le comportement, dans une parcelle, de caprins sortis quotidiennement pour la traite.

Durant un mois d'été, 80 chèvres laitières pâturent 10 ha de taillis mixte Chêne vert-Chêne pubescent (CP) dans le sud de la France. Les zones à CP, espèce la plus appétée (Léouffre et al, 1989), sont éloignées de la porte de l'enclos que les animaux empruntent en milieu de matinée

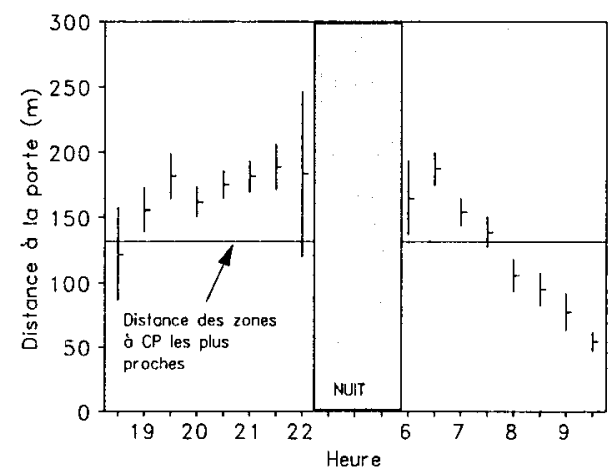

Fig 1. Moyenne interjournalière, minima et maxima (au seuil de $5 \%$ ) des distances à la porte du centre de gravité du troupeau en fonction de l'heure de la journée. pour partir à la traite et en fin d'après-midi au retour. Les choix alimentaires et les déplacements ont été observés, à l'exception de la nuit (Lecrivain, 1990), durant 21 j répartis sur les 3 premiers étés d'exploitation de la parcelle.

Que ce soit en soirée ou en matinée, les chèvres pâturent toujours intensément (taux moyen de $79 \pm 2 \%$ ) mais leur comportement spatial varie : alors qu'en soirée elles s'éloignent en une demi-heure de la porte, en matinée, elles amorcent un retour vers la sortie plus de 2 heures avant l'heure habituelle de départ de l'enclos (fig 1). Compte tenu de l'éloignement des zones à CP par rapport à la porte, ce comportement spatial a pour conséquence une probabilité d'accès au CP plus forte en soirée qu'en matinée. On observe en effet que le CP est significativement plus choisi en soirée qu'en matinée (test de Wilcoxon, $P=0,001$ ).

Si en soirée, les chèvres se déplacent comme le laisse présager leur forte attirance pour le $\mathrm{CP}$, en matinée il y a clairement eu un changement de motivation : tout se passe comme si l'enjeu ne se situait plus dans mais hors de la parcelle pâturée (distribution de concentré, d'eau, confort thermique et traite en chèvrerie...).

Le comportement d'un troupeau dans une parcelle est donc une fonction des décisions prises à différents niveaux par l'éleveur : d'une part sur l'espace pâturé lui-même (position de la porte dans l'enclos) et d'autre part sur l'organisation de la journée entière (rythme d'alimentation et de retour en chèvrerie).

Lécrivain E (1990) Proc VIlth European Grazing Workshop, Wageningen, $6 p$

Leouffre MC, Lécrivain E, Leclerc B (1989) XVI ${ }^{\theta}$ Congrès Int Herbages, 2, 1083-1084 